\title{
EDITORIAL
}

\section{LA FACULTAD DE EDUCACIÓN: NUEVA ALTERNATIVA EN LA U.D.C.A}

\author{
Germán Anzola Montero \\ Rector
}

En esta edición de la Revista Actualidad $\mathcal{E}$ Divulgación Científica es mi propósito presentar a la comunidad universitaria, una nueva alternativa académica, para quienes aspiran a adelantar su formación profesional, en la Universidad de Ciencias Aplicadas y Ambientales U.D.C.A.

El Consejo Directivo, recientemente, tomó la determinación de acoger la propuesta de la Rectoría, de crear la Facultad de Educación, cuyo propósito fundamental es apoyar las estrategias educativas del actual gobierno, en el sentido de contribuir en la construcción de una cultura de paz, que garantice la prosperidad política, económica y social, en el contexto de la reconciliación de los colombianos, en su realidad humana y ambiental.

Asumimos, que ninguna causa de paz, ninguna resolución de conflictos y, mucho menos, la construcción de una cultura de paz, tendrán un fin exitoso y sostenible, si no están mediados por un proceso formativo. La educación, por lo tanto, es la herramienta que podrá facilitar el inicio, el desarrollo y la sostenibilidad, en calidad y en tiempo, para alcanzar esta pretensión del Estado Colombiano y el fundamento para confiarle a la sociedad profesores de excelencia, en todos los niveles de formación, como factor determinante y principal garantía, para cumplir esta finalidad.

Los énfasis educativos obedecen al carisma fundacional de la U.D.C.A y a su fortaleza académica, representada también en la práctica ambiental, reconocida, a nivel nacional e internacional. La nueva facultad, fiel a esta visión, contribuirá a la producción de conocimiento y a la formación de profesores, con las competencias exigidas, para orientar en la solución de problemas y el aprovechamiento de oportunidades de desarrollo ambiental.

Los programas de Licenciatura en Ciencias Naturales y Educación Ambiental, la Especialización en Docencia para la Educación Superior y la Maestría en Educación Ambiental son una iniciativa de la Universidad, para responder a las necesidades de atención a la formación de profesores y de especialistas y garantizar, con excelencia, las exigencias planteadas por el permanente cuestionamiento que se hace a la calidad del ejercicio de la profesión docente, en todos sus niveles.

A partir de estos planteamientos, la facultad de Ciencias de la Educación de la U.D.C.A, en los niveles de Licenciatura y de Posgrado, garantizará:

- Educadores de alta calidad, base para lograr una educación de excelencia, política y exigencia emitida por el gobierno Colombiano.

- La sostenibilidad del ambiente, que depende de la formación ciudadana en conocimientos y en valores, enseñados por los educadores y apropiado por los alumnos.

- La construcción de una cultura de paz, que tiene como actores fundamentales a los educadores.

- El fortalecimiento de las sociedades del conocimiento, con miras a disponer de educadores que transfieren valores culturales, técnicos y científicos a sus alumnos.

- La construcción de escenarios de reflexión y de problematización sobre las prácticas derivadas del aula de clase.

- $\quad$ El fomento de proyectos y de redes de investigación y la evaluación del impacto de los procesos investigativos en los contextos formativos, que hacen que las personas que se inician como educadores, se interesen, permanentemente, en el quehacer científico.

- El enriquecer el proceso formativo de los educadores, con la realización de valoraciones y de mediciones rigurosas acerca del desempeño, la metodología, la actualización de contenidos y del deber ser y hacer del docente.

- Espacios de formación en diferentes lugares del país al formar educadores, cuyo ejercicio docente se adecúe a la diversidad cultural, de cada región del país. 
Los educadores de alta calidad contribuyen a fortalecer el tejido social, a través de su desempeño y del ejercicio idóneo de sus competencias, en la formación de las nuevas generaciones.
Hoy, el capital no es el factor fundamental para el desarrollo del país. No cabe ninguna duda que la educación es la base y el fundamento para ese desarrollo y, los educadores, los encargados de salvaguardar esa misión. 